\title{
Crocin promotes apoptosis of human skin cancer cells by inhibiting the JAK/STAT pathway
}

\author{
GONGFENG WANG, BAOFANG ZHANG, YANYAN WANG, SHUNLI HAN and CHENGHONG WANG
}

\begin{abstract}
Department of Traditional Chinese Medicine, The Third People's Hospital of Linyi, Linyi, Shandong 276000, P.R. China
\end{abstract}
Received April 9, 2018; Accepted October 8, 2018

DOI: $10.3892 /$ etm.2018.6865

\begin{abstract}
Pro-apoptotic effect and mechanism of crocin on skin cancer cells were investigated. After human skin cancer cells A431 and SCL-1 were processed with different concentrations of crocin in vitro $(0,0.2,0.4,0.8$ and $1.0 \mathrm{mmol} / \mathrm{l})$, cell viability was examined utilizing the methyl thiazolyl tetrazolium assay (MTT). After $24 \mathrm{~h}$ incubation, the cell viability of A431 and SCL-1 decreased with increasing concentration of crocin. This indicated that crocin is capable of inhibiting the cloning ability and proliferative ability of human skin cancer cells A431 and SCL-1 in a dose-dependent manner. Flow cytometry results showed that crocin blocked A431 and SCL-1 cells in G0/G1 phase, and promoted apoptosis. The results of western blot analysis showed that the expression of Bid, procaspase- 3 and ciprofloxacin in A431 and SCL-1 cells were positively correlated with crocin, while the expression of anti-apoptotic protein Bcl-2 was downregulated, which was negatively correlated with the concentration of crocin. The detection of JAK/STAT signaling pathway showed that the expression of Jak2 and Stat3 was downregulated, which was negatively correlated with crocin concentration. Crocin can significantly inhibit the proliferation of human skin cancer cells and induce cell cycle arrest in G0/G1 phase. Moreover, it can promote apoptosis of the cells. The apoptosis mechanism may be related to the downregulation of JAK/STAT pathway.
\end{abstract}

\section{Introduction}

Skin cancer is one of the most common malignancies in the world, and its morbidity is increasing year by year. It has become a major disease that is detrimental to human health. Skin cancers can be divided into basal cell carcinoma, squamous cell carcinoma and melanoma. It has intricate pathogenesis, which is currently considered to be attributed to environmental factors, gene mutation and viral infection.

Correspondence to: Dr Gongfeng Wang, Department of Traditional Chinese Medicine, The Third People's Hospital of Linyi, 117 Huaxia Road, Linyi, Shandong 276000, P.R. China

E-mail: ylahm716@163.com

Key words: crocin, human skin cancer cells, apoptosis, Jak2, Stat3
Skin malignancies, such as squamous cell carcinoma and malignant melanoma have no effective prevention and treatment at present. Therefore, the study of the occurrence and development mechanism of skin cancers is imperative (1).

Crocin is a less common water-soluble carotenoid (dicarboxylic acid monoglyceride) extracted from saffron $(2,3)$. Research has shown that cytoplasmic membrane rupture, nuclear pyknosis and cell apoptosis were observed in cervical carcinoma cells after the cells were treated with crocin (4). Crocin inhibited the growth of tumor cells, the mechanism of which may be related to its strong antitumor cytotoxicity (5).

Tumor development is a multi-gene, multi-step, multi-stage sophisticated process. The biological characteristics of tumor cells were mainly manifested as uncontrolled proliferation, blocked apoptosis and strong invasiveness. In normal tissues, cell proliferation and apoptosis is under a precisely regulated dynamic balance status. Nevertheless, this balance is broken in tumor tissues. Tumor cells begin to resist apoptosis, immune destruction and other mechanisms of elimination. As a result, tumor cells cannot be cleared in time, which is the determinant of unlimited tumor proliferation (6).

The purpose of this study was to investigate the effects of crocin on proliferation and apoptosis of human skin cancer cells A431 and SCL-1, also to preliminarily explore its underlying mechanism.

\section{Materials and methods}

Materials and reagents. Human skin cancer cells A431 and SCL-1 were provided by the Dermatology Laboratory of Nanjing Medical University First Affiliated Hospital (Nanjing, China). RPMI-1640 medium was purchased from Hyclone (GE Healthcare Life Sciences, Logan, UT, USA). Fetal bovine serum, trypsin, penicillin and streptomycin were purchased from Gibco; Thermo Fisher Scientific, Inc., Waltham, MA, USA. Crocin and methyl thiazolyl tetrazolium (MTT) were purchased from Sigma-Aldrich; Merck KGaA, Darmstadt, Germany. Annexin V-FITC apoptosis detection kit was purchased from Bender MedSystems (Thermo Fisher Scientific, Inc.). Bid, procaspase-3, Jak2, Stat3 and Bcl-2 antibodies were purchased from Santa Cruz Biotechnology, Inc. (Dallas, TX, USA). Polyclonal goat anti-rabbit IgG-HRP secondary antibody (cat. no. sc-2004; dilution, 1:500) was purchased from Santa Cruz Biotechnology, Inc. (Dallas, TX, USA). 
Preparation of crocin solution. Under sterile condition, $20 \mathrm{mg}$ of crocin and $12.5 \mathrm{mg}$ of EDTA was dissolved into $4 \mathrm{ml}$ of 3 -fold distilled water for stock solution with a concentration of $50 \mathrm{mmol} / 1$ and stored at $4^{\circ} \mathrm{C}$.

Cell culture. A431 and SCL-2 cells were cultured in RPMI-1640 medium containing 10\% fetal bovine serum (FBS), $100 \mathrm{U} / 1$ penicillin and $100 \mu \mathrm{g} / \mathrm{ml}$ streptomycin in incubator with $5 \% \mathrm{CO}_{2}$ at $37^{\circ} \mathrm{C}$. The cells were subcultured routinely with trypin digestion containing $0.02 \%$ EDTA.

Cell transfection. A431 and SCL-1 cells in the logarithmic growth phase were inoculated into cell culture plates according to the appropriate cell numbers and cultured overnight. The following day, the cells were treated with different concentrations $(0,0.4$ and $0.8 \mathrm{mM})$ of crocin to detect the cell phenotypes. Alternatively, according to the instructions of Lipofectamine 2000, the cells were transfected with Jak2 overexpression plasmid (pcDNA-Jak2) for $8 \mathrm{~h}$, and then replaced with complete medium for further culture. The related phenotypes were detected after the transfection process.

Cell viability assay. Cell viability was determined by MTT assay. A431 and SCL-1 cells in logarithmic growth phase were harvested for cell counting. The cell density was adjusted for a concentration of $2 \times 10^{4}$ cells $/ \mathrm{ml}$ by Dulbecco's modified Eagle's medium (DMEM), then seeded into 96-well plates and incubated at $37^{\circ} \mathrm{C}$ in a $5 \% \mathrm{CO}_{2}$ saturated humidity incubator. After overnight adherence, the supernatant was aspirated and different concentrations of crocin (concentration $0,0.2$, $0.4,0.8$ and $1.0 \mathrm{mmol} / \mathrm{l}$ ) were added to corresponding treatments for another $24 \mathrm{~h}$ incubation. On the other hand, the same concentration $(0.8 \mathrm{mmol} / \mathrm{l})$ of crocin was added and cultured for $0,6,12,24,48$ and $72 \mathrm{~h}$, respectively. A total of $20 \mu \mathrm{l}$ MTT (5 g/l) solution was added to each well for $4 \mathrm{~h}$ and centrifuged at $1,750 \mathrm{x} \mathrm{g}$ for $10 \mathrm{~min}$ at $4^{\circ} \mathrm{C}$. The reaction was terminated by discarding the supernatant and adding $150 \mu \mathrm{l}$ dimethylsulphoxide (DMSO) per-well. The sample was placed on a shaker at shaking speed for $10 \mathrm{~min}$. The OD value was measured using spectrophotometer (Hitachi, Ltd., Tokyo, Japan) at $570 \mathrm{~nm}$ wavelength. Each treatment was set up in triplicates. Inhibition rate was calculated as follows: Inhibition rate $(\%)=($ control group $\mathrm{A}$ - experimental group $\mathrm{A}) / \mathrm{control}$ group A x $100 \%$.

Colony formation assay. Cells in logarithmic growth phase were converted into cell suspension status by using conventional digestion and passage method. The cells were dissociated thoroughly and repeatedly to make the cell percentage of each single cell above $95 \%$. A total of 200 cells were taken and seeded in 6-well plates with $2 \mathrm{ml}$ medium and shaken gently on a shaker. Afterwards the plate was placed and incubated at $37^{\circ} \mathrm{C}$ in a $5 \% \mathrm{CO}_{2}$ saturated humidity incubator for another 2 weeks. The formation of clones was monitored under a microscope (BX-42; Olympus Corporation, Tokyo, Japan). The culture medium was removed when clones were grown to the appropriate number and size. Cells were fixed by adding $4 \%$ polyoxymethylene for $10 \mathrm{~min}$, and then rinsed with phosphatebuffered saline (PBS) twice. After stained with hematoxylin for $10 \mathrm{~min}$, the cells were rinsed by PBS and air dried. After that the cells were photographed and counted under the microscope (BX-42; Olympus Corporation).

EDU staining experiment. EDU kit was used for the experiment. Cells in logarithmic growth phase were collected for routine digestion, centrifugation, resuspension and counting. Harvested cells were seeded into 96-well plates at a density of $4 \times 10^{3}$ cells/well. After the cells grew adherently and in proper concentration, EDU staining procedure was performed following the kit instructions. After staining the cells were photographed and counted under the fluorescence microscope (IX70; Olympus Corporation). Samples that appeared in $>3$ random sights were selected and calculated utilizing IPWIN60 software for the number of cells in S phase out of every 200 cells. The ratio was calculated by dividing the number of cells in S phase by 200, and then by further statistical analysis.

Flow cytometric analysis for evaluating apoptosis index and the cell cycle. The human skin cancer cells were collected and adjusted to a concentration of $1 \times 10^{5} / \mathrm{ml}$, and then seeded on 6 -well plates with $2 \mathrm{ml}$ per well. After the cells were incubated for $24 \mathrm{~h}$, supernatant was removed and serum-free medium containing $0,0.4,0.8 \mathrm{mmol} / \mathrm{l}$ of crocin was added. The 6 -well plates were placed into the incubator again for another $24 \mathrm{~h}$ culture for following tests. For apoptosis assay, the cells were washed twice with PBS, then collected at a density of $5 \times 10^{5}$. After centrifugation at $1,500 \mathrm{x}$ g for $10 \mathrm{~min}$ at $20^{\circ} \mathrm{C}, 500 \mu \mathrm{l}$ of binding buffer was added to resuspend cells. A total of $5 \mu \mathrm{l}$ of Annexin V-FITC and $5 \mu 1$ of pro-pidium iodide (PI) was added and mixed. The reaction was protected from light at room temperature for $10 \mathrm{~min}$. Finally, apoptosis index was evaluated utilizing the flow cytometer. To detect the cell cycle phrase distribution, the cells were washed once with PBS and then collected and adjusted to a concentration of $1 \times 10^{6} / \mathrm{ml}$ after centrifugation. The sample was stabilized with $70 \%$ ethanol and preserved at $4^{\circ} \mathrm{C}$. The fixative was then washed with PBS before staining. A total of $100 \mu \mathrm{l}$ RNase A was added and heated up to $37^{\circ} \mathrm{C}$ in water bath for approximately $30 \mathrm{~min}$. Then the sample was treated with $400 \mu$ l PI staining mix and incubated in the dark at $4^{\circ} \mathrm{C}$. After $30 \mathrm{~min}$, the red fluorescence at $488 \mathrm{~nm}$ wavelength was evaluated and recorded utilizing the flow cytometer.

Western blot analysis. According to the amount of cells, appropriate amount of RIPA cell lysis solution was added. RIPA lysis and extraction buffer (cat. no. 89900; Thermo Fisher Scientific, Waltham, MA, USA) was used for the western blot analysis. Cell lysate was collected, sonicated on ice for $1 \mathrm{~min}$, and centrifuged. After centrifugation at $10,000 \times \mathrm{g}$ for $10 \mathrm{~min}$ at $4^{\circ} \mathrm{C}$, the supernatant was collected to determine the protein concentration by bicincho-ninic acid (BCA) method. A total of $30 \mu \mathrm{g}$ protein sample was loaded on $10 \%$ sodium dodecyl sulphate (SDS) gel for each well. After the electrophoresis, the gel was transferred to the polyvinylidene fluoride (PVDF) membrane and blocked using $5 \%$ fat-free milk for $1 \mathrm{~h}$. After that, corresponding primary antibodies was added to each corresponding sample and incubated at $4^{\circ} \mathrm{C}$ overnight. Then the corresponding secondary antibody were added for $1 \mathrm{~h}$ incubation at room temperature. 
A

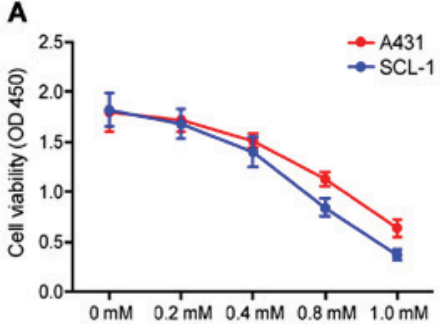

B

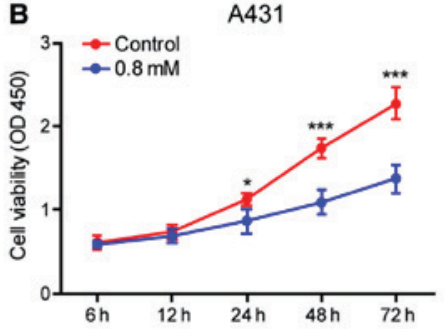

SCL-1

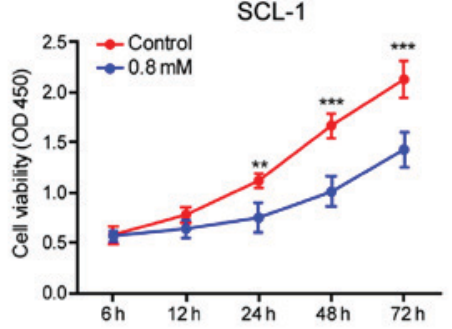

D

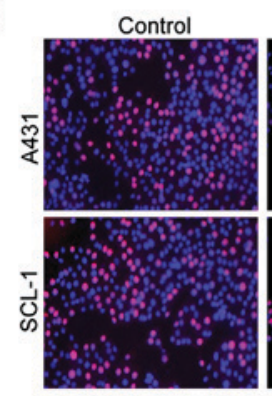

$0.4 \mathrm{mM}$

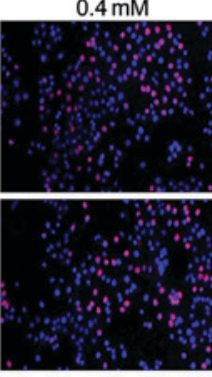

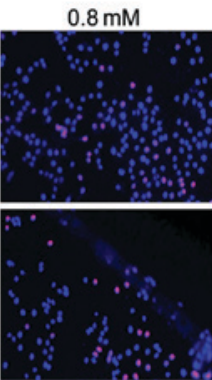

Figure 1. Crocin inhibits the proliferation of skin cancer cells. (A) At $24 \mathrm{~h}$ after skin cancer cells (A431 and SCL-1) were cultured by culture medium containing different concentrations of crocin, MTT assay showed that cell viability decreases with increasing crocodile concentration. (B) Skin cancer cells were treated with $0.8 \mathrm{mM}$ crocin, and the viability of A431 and SCL-1 cells was measured by MTT assay. (C and D) Cultured skin cancer cells with two media each contains 0.4 and $0.8 \mathrm{mM}$ crocin separately, (C) utilizing the cloning ability of A431 and SCL-1 cells by plate clone assay; (D) utilizing EDU staining experiment to evaluate the growth ability of A431 and SCL-1 cells. "Compared with $6 \mathrm{~h}, \mathrm{P}<0.05 ;{ }^{* *}$ compared with $6 \mathrm{~h}, \mathrm{P}<0.01 ;{ }^{* * *}$ compared with $6 \mathrm{~h}, \mathrm{P}<0.001$.

A

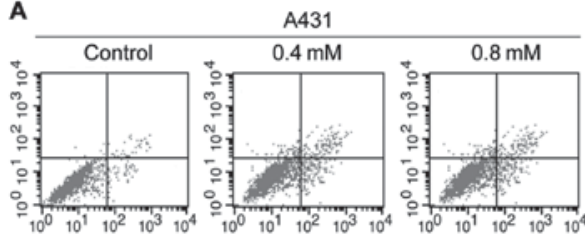

A431

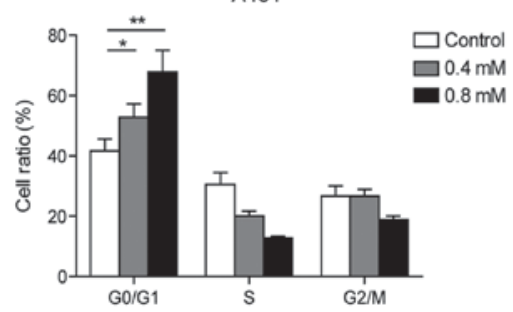

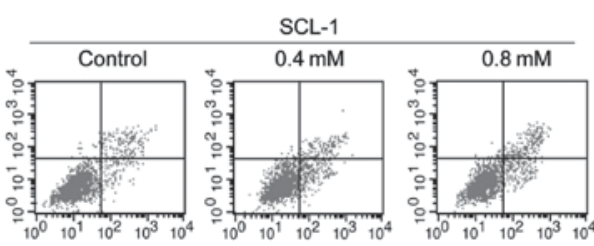

SCL-1

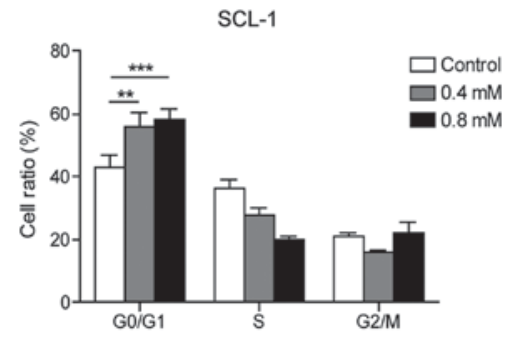

Figure 2. Crocin inhibits apoptosis and the cell cycle of skin cancer cells. Skin cancer cells were cultured in two media each contains 0.4 and $0.8 \mathrm{mM}$ crocin. (A) Flow cytometer was used to detect the apoptosis of A431 and SCL-1 cells. (B) Flow cytometer was used to detect the cell cycle expression of A431 and SCL-1 cells. ${ }^{*} \mathrm{P}<0.05 ;{ }^{* *} \mathrm{P}<0.01 ;{ }^{* * *} \mathrm{P}<0.001$.

Primary mouse monoclonal B-cell lymphoma-2 (Bcl-2) antibody (cat. no. ab59348; dilution, 1:500); rabbit polyclonal Caspase-3 antibody (cat. no. ab13847; dilution, 1:500); rabbit monoclonal Bid antibody (cat. no. ab32060; dilution, 1:500); rabbit monoclonal JAK2 antibody (cat. no. ab108596; dilution, 1:500); mouse monoclonal STAT3 antibody (cat. no. ab119352; dilution, 1:500); rabbit polyclonal GAPDH antibody (cat. no. ab37168; dilution, 1:500) and secondary goat anti-rabbit (HRP) IgG antibody (cat. no. ab6721; dilution, 1:2,000) were all purchased from Abcam (Cambridge, MA, USA). Lastly enhanced chemiluminescent method was used to expose the protein band. The experiment was repeated three times independently.
Statistical analysis. The measurement data were expressed as mean \pm standard deviation, utilizing SPSS 11.0 (SPSS Inc., Chicago, IL, USA) software for statistical analysis. t-test was used to compare two groups. $\mathrm{P}<0.05$ was considered to indicate a statistically significant difference.

\section{Results}

Crocin inhibits the proliferation of human skin cancer cells A431 and SCL-1.Crocin significantly inhibited the proliferation of A431 and SCL-1 cells and in a dose-dependent manner. The maximum inhibitory effect appeared at $1 \mathrm{mM}$ (Fig. 1A), and the effect increased with the training time (Fig. 1B). 

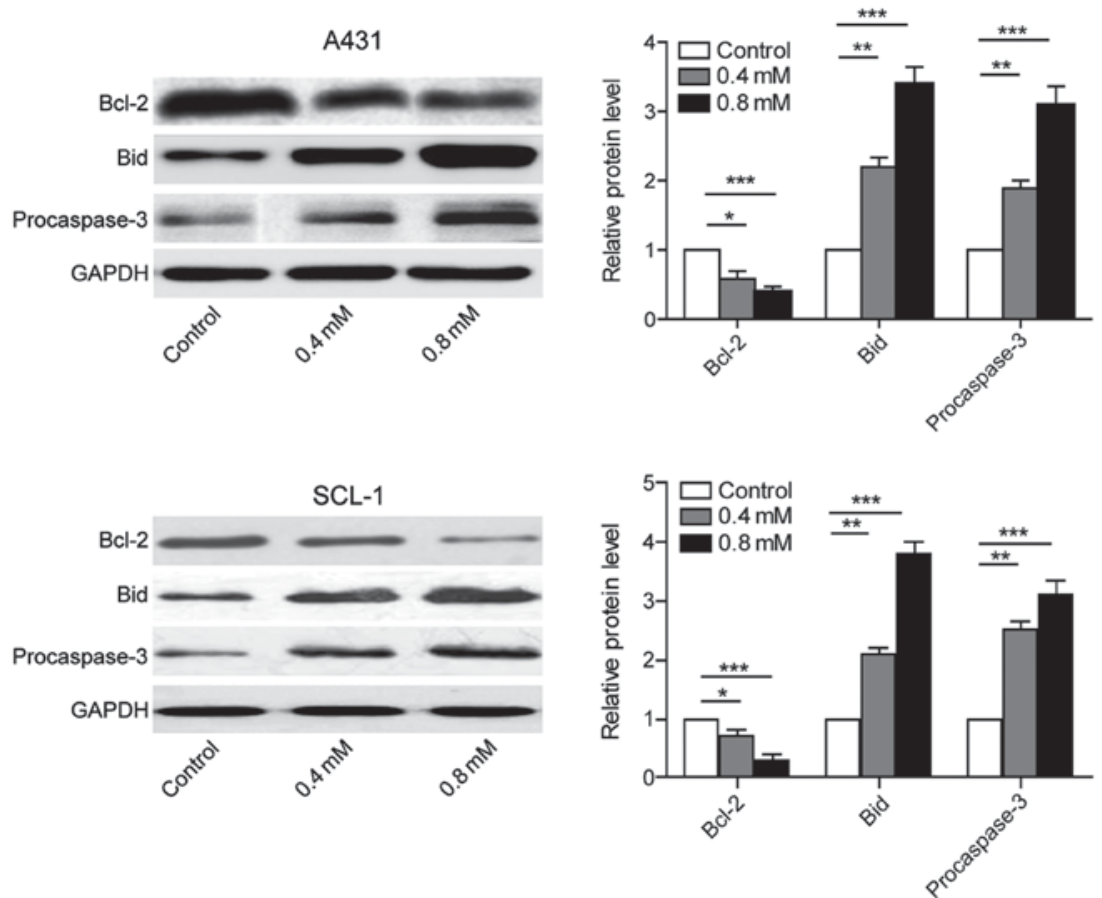

Figure 3. Crocin inhibits anti-apoptotic proteins and promotes the expression of pro-apoptotic proteins. Skin cancer cells were cultured in two media each contains 0.4 and $0.8 \mathrm{mM}$ crocin. Western blot analysis was used to detect the expression of anti-apoptotic protein (Bcl-2) and pro-apoptotic proteins (Bid and procaspase-3) in A431 and SCL-1 cells. ${ }^{*} \mathrm{P}<0.05 ;{ }^{* * *} \mathrm{P}<0.01 ;{ }^{* * * *} \mathrm{P}<0.001$.

A
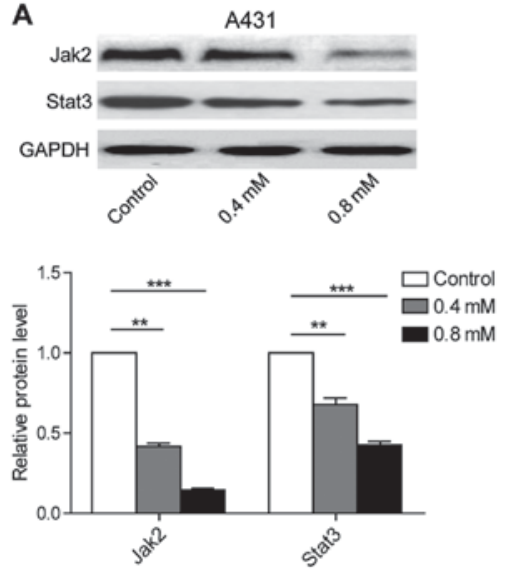

B

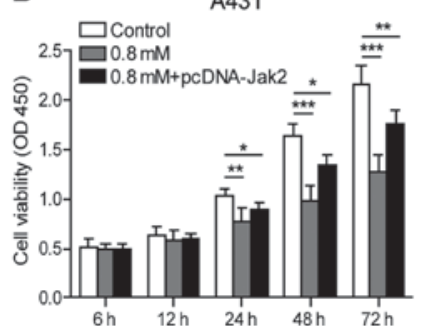

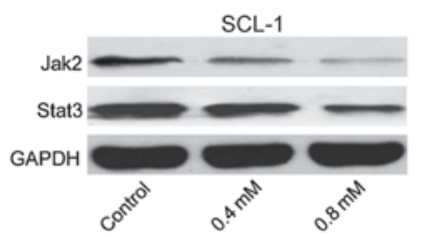

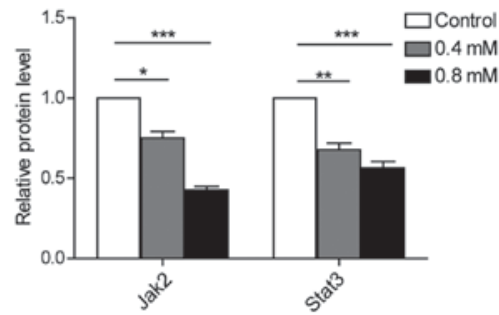

SCL-1

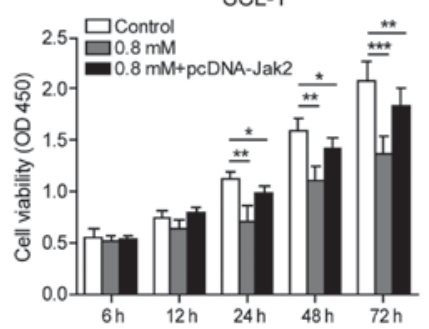

Figure 4. Crocin inhibits the JAK/STAT signaling pathway and promotes apoptosis of skin cancer cells. (A) A431 and SCL-1 cells were cultured with two media each contains 0.4 and $0.8 \mathrm{mM}$ crocin, for the purpose of detecting the protein expression of Jak2 and Stat 3 through western blot analysis. (B) A431 and SCL-1 cells were cultured with a medium containing $0.8 \mathrm{mM}$ crocin, or overexpressed JAK2, for the purpose of testing the cell viability utilizing the MTT assay. ${ }^{*} \mathrm{P}<0.05 ;{ }^{* *} \mathrm{P}<0.01 ;{ }^{* * *} \mathrm{P}<0.001$.

Crocin was also found capable of constraining the clonogenic capacity of human skin cancer cells. Also, the group using the concentration of $0.8 \mathrm{mmol} / \mathrm{l}$ crocin had enhanced inhibitory effects compared to $0.4 \mathrm{mmol} / \mathrm{l}$ (Fig. 1C). Furthermore, EDU experimental results showed that crocin can inhibit the viability of human skin cancer cells in a concentration-dependent 
manner (Fig. 1D). In conclusion, the above results showed that crocin has potential therapeutic effect on skin cancer.

Crocin inhibits the cell cycle transition and cell proliferation of A431 and SCL-1 cells. Flow cytometry analysis showed that crocin could induce apoptosis of A431 and SCL-1 cells to a certain extent, which was positively correlated with the concentration (Fig. 2A). Moreover, compared with the control group, it was found that crocin could arrest A431 and SCL-1 cells in G0/G1 phase (Fig. 2B).

Crocin inhibits the expression of anti-apoptotic proteins and promotes the expression of pro-apoptotic proteins. A431 and SCL-1 cells were cultured individually with $0,0.4,0.8 \mathrm{mmol} / \mathrm{l}$ crocin. The proteins were collected after $24 \mathrm{~h}$ to evaluate the expression of anti-apoptotic protein $\mathrm{Bcl}-2$, pro-apoptotic protein Bid and procaspase-3. The results showed that the expression of anti-apoptotic protein was downregulated, while the expression of pro-apoptotic protein was upregulated. Also, the group using the concentration of $0.8 \mathrm{mmol} / \mathrm{l}$ crocin exerted better effects than that of $0.4 \mathrm{mmol} / \mathrm{l}$. These results suggested that crocin induced apoptosis of skin cancer cells A431 and SCL-1 by regulating apoptosis pathway (Fig. 3).

Crocin has inhibitory effects on JAK/STAT signaling pathway in human skin cancer cells. A431 and SCL-1 cells were cultured in medium containing $0,0.4$ and $0.8 \mathrm{mmol} / 1$ crocin respectively for the purpose of evaluating the expression of Jak2 and Stat 3 proteins using western blot analysis. The results showed that crocin can inhibit the expression of Jak2 and Stat 3 protein in a dose-dependent pattern (Fig. 4A). After crocin treatment and overexpressing Jak2 at the same time, cell viability result by MTT assay showed that the cell viability of $0.8 \mathrm{mmol} / 1$ crocin group showed a significant decrease at 24,48 and $72 \mathrm{~h}$ compared with the control group. The overexpression of Jak2 partially reversed the inhibitory effects of crocin, further suggesting that crocin could inhibit the Jak2/Stat 3 pathway in human skin cancer cells to facilitate apoptosis (Fig. 4B).

\section{Discussion}

In recent years, traditional Chinese medicine treatment for various tumors has become a hotspot and focus of oncology field, considering its benefit of reduced toxicity and fewer side effects. Previous studies indicated that the traditional Chinese medicine treatment could inhibit proliferation, promote apoptosis and exert antitumor effects using other mechanisms $(3,7)$. Studies have demonstrated that crocin extracted from saffron has prominent inhibitory effects on a variety of cancer cell proliferation $(5,8,9)$ by acting on various pathways, including apoptosis pathway (10-12).

Apoptotic pathways are mainly regulated by endogenous pathways, exogenous pathways and endoplasmic reticulum stress pathways. The endogenous pathway is also a mitochondrial-dependent pathway, in which the mitochondrial membrane potential changes after the cells receive the exogenous signal. The increased mitochondrial membrane permeability enables the release of mitochondrial protein into the cytoplasm, thereby inducing apoptosis. Exogenous pathway is induced by the binding of death ligand and death receptor, which recruits adapter protein and forms a death-inducing signaling complex (DISC) with the caspase- 8 precursor, thus activating caspase-3 for apoptotic induction. The cellular endoplasmic reticulum stress signal is activated when the cellular misfolded protein accumulates excessively, triggering apoptotic signals and promoting apoptosis through a series of apoptosis-related molecules (13). The Bcl-2 family is a type of important regulatory protein in the process of apoptosis. The balance of pro-apoptotic proteins and anti-apoptotic proteins in this family affects whether the cells survive or die. When cells receive a survival signal, anti-apoptotic molecules such as Bcl-2, Mcl-1 and Bcl-w are activated. In contrast, the pro-apoptotic protein such as Bid, Bax would be activated to induce apoptosis of cells, when the cells receive the pro-apoptotic signal (14). In this study, we preliminary demonstrated that saffron can inhibit the proliferation of skin cancer cells as well as promote apoptosis. While detecting apoptosis-related proteins, we found out that the expression of anti-apoptotic protein $\mathrm{Bcl}-2$ was downregulated, while the expression of pro-apoptotic protein Bid and procaspase-3 was upregulated.

Recent studies have found that JAK/STAT signaling pathway was activated abnormally in a variety of tumor tissues, which has an immense influence on tumor progression $(15,16)$. JAK/STAT signaling pathway is an important intracellular signal transduction pathway involved in a variety of physiological processes such as cell growth, differentiation and apoptosis (17). STAT persistent specific signals, especially STAT3 and STAT5, can encode apoptosis inhibitors. It can also stimulate cell proliferation and inhibit apoptosis by upregulating the effect of Bcl-xl, Bcl-1 cyclin D1/D2 and $\mathrm{c}-\mathrm{Myc}$ genes, thereby participating in the formation of tumors $(18,19)$. The continuous activation of STAT3, which is capable of promoting malignant transformation, has been corroborated as an oncogene (20). Under the pathological conditions, the downstream target genes of STAT signals, such as Bcl-2, caspases, survivin, Bcl-xl, cyclin D1, p21 and VEGF, Mcl-1, c-Myc, c-Jun and Fas, are abnormally activated and involved in a variety of pathophysiological processes such as cell proliferation, differentiation, malignant transformation, and apoptosis inhibition (21-23). In this study, the expression of Jak2 and Stat 3 was downregulated after crocin treatment of human skin cancer cells. In the combination group with both Jak2 expression and crocin treatment, there was no evidence of any tumor-promoting effect in JAK/STAT pathway. This illustrated that crocin can play a tumor-promoting role by inhibiting Jak2/Stat3 pathway in human skin cancer.

In conclusion, crocin could inhibit the proliferation of A431 and SCL-1 skin cells and promote apoptosis. The possible mechanism of apoptosis is to inhibit the Jak2/Stat 3 pathway, downregulate the anti-apoptotic protein $\mathrm{Bcl}-2$ expression and enhance the levels of pro-apoptotic protein Bid and procaspase-3.

\section{Acknowledgements}

Not applicable.

\section{Funding}

No funding was received. 


\section{Availability of data and materials}

All data generated or analyzed during this study are included in this published article.

\section{Authors' contributions}

GW and BZ designed the study and performed the experiments, GW, YW and SH cultured the cells, BZ and CW collected the data, GW and YW analyzed the data, GW prepared the manuscript. All authors read and approved the final study.

\section{Ethics approval and consent to participate}

Not applicable.

\section{Patient consent for publication}

Not applicable.

\section{Competing interests}

The authors declare that they have no competing interests.

\section{References}

1. Eisemann N, Waldmann A, Geller AC, Weinstock MA Volkmer B, Greinert R, Breitbart EW and Katalinic A: Non-melanoma skin cancer incidence and impact of skin cancer screening on incidence. J Invest Dermatol 134: 43-50, 2014.

2. Jagadeeswaran R, Thirunavukkarasu C, Gunasekaran P, Ramamurty $\mathrm{N}$ and Sakthisekaran $\mathrm{D}$ : In vitro studies on the selective cytotoxic effect of crocetin and quercetin. Fitoterapia 71: 395-399, 2000.

3. Jnaneshwari S, Hemshekhar M, Santhosh MS, Sunitha K, Thushara R, Thirunavukkarasu C, Kemparaju K and Girish KS: Crocin, a dietary colorant, mitigates cyclophosphamide-induced organ toxicity by modulating antioxidant status and inflammatory cytokines. J Pharm Pharmacol 65: 604-614, 2013.

4. Escribano J, Alonso GL, Coca-Prados M and Fernandez JA: Crocin, safranal and picrocrocin from saffron (Crocus sativus L.) inhibit the growth of human cancer cells in vitro. Cancer Lett 100: 23-30, 1996.

5. Abdullaev FI and Espinosa-Aguirre JJ: Biomedical properties of saffron and its potential use in cancer therapy and chemoprevention trials. Cancer Detect Prev 28: 426-432, 2004.

6. Kerr JF, Wyllie AH and Currie AR: Apoptosis: A basic biological phenomenon with wide-ranging implications in tissue kinetics. Br J Cancer 26: 239-257, 1972.

7. Ishizuka F, Shimazawa M, Umigai N, Ogishima H, Nakamura S, Tsuruma $\mathrm{K}$ and Hara $\mathrm{H}$ : Crocetin, a carotenoid derivative, inhibits retinal ischemic damage in mice. Eur J Pharmacol 703: $1-10,2013$.

8. Abdullaev FI: Cancer chemopreventive and tumoricidal properties of saffron (Crocus sativus L.). Exp Biol Med (Maywood) 227: 20-25, 2002.

9. García-Olmo DC, Riese HH, Escribano J, Ontañón J, Fernandez JA, Atiénzar M and García-Olmo D: Effects of long-term treatment of colon adenocarcinoma with crocin, a carotenoid from saffron (Crocus sativus L.): An experimental study in the rat. Nutr Cancer 35: 120-126, 1999.
10. Hawkins RE, Russell SJ and Winter G: Selection of phage antibodies by binding affinity. Mimicking affinity maturation. J Mol Biol 226: 889-896, 1992.

11. Smith GP: Filamentous fusion phage: Novel expression vectors that display cloned antigens on the virion surface. Science 228: 1315-1317, 1985.

12. Davies J and Riechmann L: An antibody VH domain with a lox-Cre site integrated into its coding region: Bacterial recombination within a single polypeptide chain. FEBS Lett 377: 92-96, 1995.

13. Xu C, Bailly-Maitre B and Reed JC: Endoplasmic reticulum stress: Cell life and death decisions. J Clin Invest 115: 2656-2664, 2005.

14. Azmi AS, Wang Z, Philip PA, Mohammad RM and Sarkar FH: Emerging Bcl-2 inhibitors for the treatment of cancer. Expert Opin Emerg Drugs 16: 59-70, 2011.

15. Lin Q, Lai R, Chirieac LR, Li C, Thomazy VA, Grammatikakis I, Rassidakis GZ, Zhang W, Fujio Y, Kunisada K, et al: Constitutive activation of JAK3/STAT3 in colon carcinoma tumors and cell lines: Inhibition of JAK3/STAT3 signaling induces apoptosis and cell cycle arrest of colon carcinoma cells. Am J Pathol 167: 969-980, 2005.

16. Gao B, Shen X, Kunos G, Meng Q, Goldberg ID, Rosen EM and Fan S: Constitutive activation of JAK-STAT3 signaling by BRCA1 in human prostate cancer cells. FEBS Lett 488: 179-184, 2001.

17. Grandis JR, Drenning SD, Zeng Q, Watkins SC, Melhem MF, Endo S, Johnson DE, Huang L, He Y and Kim JD: Constitutive activation of Stat 3 signaling abrogates apoptosis in squamous cell carcinogenesis in vivo. Proc Natl Acad Sci USA 97: 4227-4232, 2000.

18. Bromberg $\mathrm{J}$ and Darnell JE Jr: The role of STATs in transcriptional control and their impact on cellular function. Oncogene 19: 2468-2473, 2000.

19. Dell'Albani P, Kahn MA, Cole R, Condorelli DF, Giuffrida-Stella AM and de Vellis J: Oligodendroglial survival factors, PDGF-AA and CNTF, activate similar JAK/STAT signaling pathways. J Neurosci Res 54: 191-205, 1998.

20. Leong PL, Andrews GA, Johnson DE, Dyer KF, Xi S, Mai JC, Robbins PD, Gadiparthi S, Burke NA, Watkins SF, et al: Targeted inhibition of Stat3 with a decoy oligonucleotide abrogates head and neck cancer cell growth. Proc Natl Acad Sci USA 100: 4138-4143, 2003

21. Xia L, Wang L, Chung AS, Ivanov SS, Ling MY, Dragoi AM, Platt A, Gilmer TM, Fu XY and Chin YE: Identification of both positive and negative domains within the epidermal growth factor receptor $\mathrm{COOH}$-terminal region for signal transducer and activator of transcription (STAT) activation. J Biol Chem 277: 30716-30723, 2002.

22. Bromberg JF, Wrzeszczynska MH, Devgan G, Zhao Y, Pestell RG, Albanese C and Darnell JE Jr: Stat3 as an oncogene. Cell 98: 295-303, 1999.

23. Niu G, Wright KL, Huang M, Song L, Haura E, Turkson J, Zhang S, Wang T, Sinibaldi D, Coppola D, et al: Constitutive Stat3 activity up-regulates VEGF expression and tumor angiogenesis. Oncogene 21: 2000-2008, 2002.

This work is licensed under a Creative Commons Attribution-NonCommercial-NoDerivatives 4.0 International (CC BY-NC-ND 4.0) License. 